\title{
Treatment of vertebrobasilar system aneurysms: a surgical dead end? - comment on Szmygin et al., Polish Journal of Neurology and Neurosurgery, 2021
}

\author{
Jacek Szczygielski ${ }^{1,2}$, Przemysław Grzegorzewski ${ }^{1}$ \\ ${ }^{1}$ Department of Neurosurgery, Institute of Medical Sciences, University of Rzeszow, Poland \\ ${ }^{2}$ Department of Neurosurgery, Saarland University, Faculty of Medicine and Saarland University Medical Centre, \\ Homburg/Saar, Germany
}

In the (now canonical) work 'Seven aneurysms' (a handbook guiding readers through the microsurgical treatment of cerebral aneurysmatic malformations), the great author Michael T. Lawton writes: "Aneurysm surgery is, and should remain, an important element of neurosurgical culture, even as endovascular techniques advance in popularity and sophistication." [1]. However, maintaining this legacy, based mostly on the hands-on experience of generations of neurosurgeons, is becoming an increasingly difficult task, in particular regarding the technically more demanding, and less commonly treated, aneurysms. Growing interest in endovascular strategies is clearly mirrored in the rising number of patients being treated with endovascular techniques at a time when the clipping rate is falling or remaining relatively constant; this trend is being seen across the world [2,3] and also in Poland [4]. Nonetheless, it would be a premature step to grimly pronounce the eclipse of clipping culture. The vivid discussion as to the pros and cons of both therapy methods seems to be fuelled by numerous reports appraising the value of coiling or clipping in different constellations of cerebral aneurysmal disease, regarding aneurysm rupture, the age of the patient, and, particularly, the size and anatomical location of the aneurysm.

The work by Szmygin et al. [5] published in the current issue of the Polish Journal of Neurology and Neurosurgery is an important contribution, fuelling this debate in regard to aneurysms located in the posterior part of the cerebral circulation.

In Szmygin et al.s opinion, having studied the previous evidence, the treatment of vertebrobasilar aneurysms in general carries a significant periprocedural risk that seems to be acceptably low in the cases treated with use of endovascular procedures, including plain coiling, stent- or balloon-assisted coiling or flow diversion. Szmygin et al.s own data was gathered in a population of 44 patients followed up after coiling of a vertebrobasilar aneurysm over a period of at least six months. Szmygin et al. documented the procedural complication rate to be as low as $4.5 \%$. They have also reported that complete, or at least sufficient, aneurysm occlusion could be achieved in over $95 \%$ of cases. These results are not far away from those published by Gruber et al. [6], and even better than those obtained in larger series by Eskridge et al. (150 patients, 75\% success rate) [7] and Pandey et al. (247 patients, $87.5 \%$ success rate) [8]. In addition, some established economic calculations (including length of hospital stay and total treatment costs) tip the scales in favour of endovascular treatment over microsurgical clipping in this specific anatomical location of aneurysms both ruptured and unruptured $[9,10]$.

Bearing these impressive outcome statistics of endovascular treatment in mind, what conclusions should be drawn for neurosurgeons versatile in microsurgical approaches and experienced in aneurysm treatment? Should we limit our participation to cases with multiple aneurysms, drawing a firm line between catchment areas for microsurgical vs. endovascular treatment (as for example described by James Ling et al. [11]? Certainly, this case report is a prime example of excellent cooperation between both specialisms, an example to be followed even if the microsurgical and endovascular treatment modes are provided not by one dual-trained or hybrid specialist but rather by different teams [12]. Or, possibly, should the microsurgical treatment of a posterior circulation aneurysm be limited to the occasional case where surgery needs to be performed for another reason or in the case of opportunely located multiple aneurysms? Or perhaps we

Address for correspondence: Jacek Szczygielski, Department of Neurosurgery, Institute of Medical Sciences, University of Rzeszow, Poland;

e-mail: jacek.szczygielski@vp.pl

Received: 22.11.2021 Accepted: 23.11.2021 Early publication date: 2.12.2021

This article is available in open access under Creative Common Attribution-Non-Commercial-No Derivatives 4.0 International (CC BY-NC-ND 4.0) license, allowing to download articles and share them with others as long as they credit the authors and the publisher, but without permission to change them in any way or use them commercially. 
should abandon clipping aneurysms in the vertebrobasilar area completely?

In our opinion, this is not the case. Certainly, the advantages of the coiling procedure in the vertebrobasilar area have been clearly delineated by several analyses, including the publication under discussion here. However, recent advances in microsurgical techniques of neurovascular procedures, including endoscopic visualisation [13-15] and bypass techniques $[16,17]$ still allow an appreciation of the microsurgical treatment of posterior circulation aneurysms to be either a crucial amendment, or a valid competitive therapy, to endovascular procedures [18-20], with success rates of $88 \%[21,22]$ up to $98 \%$ [19] (in a series of 217 surgical patients reported by Sansai et al.). This option is of great value especially if for any reason coiling or flow diversion seem to carry a lower chance of success than expected, e.g. due to complex neck anatomy or if a more durable treatment is desired [20,22, 23].

In conclusion, the study by Szmygin et al. and previous reports on the efficacy of endovascular treatment in the vertebrobasilar area are very valuable signposts for all specialists (including neurosurgeons, neuroradiologists, neurologists and neurointensivists), who plan the route of treatment for patients with aneurysms of the vertebrobasilar area.

However, for all those engaged in microsurgical aneurysm clipping, the evidence should not be interpreted as signalling a 'dead end' but rather a sign indicating a bumpy road ahead, encouraging travel along the treatment path of these challenging cases as members of a multidisciplinary crew, instead of just turning around and giving up when the road becomes steep and challenging.

\section{References}

1. Lawton MT. Seven aneurysms - Tenets and techniques for clipping. Thieme Medical Publishers Inc., New York 2010.

2. Lin N, Cahill KS, Frerichs KU, et al. Treatment of ruptured and unruptured cerebral aneurysms in the USA: a paradigm shift. J Neurointerv Surg. 2018; 10(Suppl 1): i69-i76, doi: 10.1136/jnis.2011.004978. rep, indexed in Pubmed: 30037962.

3. Zhang X, Li L, Hong Bo, et al. A systematic review and meta-analysis on economic comparison between endovascular coiling versus neurosurgical clipping for ruptured intracranial aneurysms. World Neurosurg. 2018; 113: 269-275, doi: 10.1016/j.wneu.2018.02.078, indexed in Pubmed: 29476995.

4. Tykocki T, Kostyra K, Czyż M, et al. Four-year trends in the treatment of cerebral aneurysms in Poland in 2009-2012. Acta Neurochir (Wien). 2014; 156(5): 861-868, doi: 10.1007/s00701-014-2006-z, indexed in Pubmed: 24499992.

5. Szmygin $\mathrm{P}$, Szmygin M, Roman $\mathrm{T}$, et al. Endovascular treatment of vertebrobasilar system aneurysms - long term results. Neurol Neurochir Pol 2021; 55 (6): 567-573, doi: 10.5603/PJNNS.a2021.0079, indexed in Pubmed: 34704602.

6. Gruber DP, Zimmerman GA, Tomsick TA, et al. A comparison between endovascular and surgical management of basilar artery apex aneurysms. J Neurosurg. 1999; 90(5): 868-874, doi: 10.3171/ jns.1999.90.5.0868, indexed in Pubmed: 10223453.
7. Eskridge JM, Song JK. Endovascular embolization of 150 basilar tip aneurysms with Guglielmi detachable coils: results of the Food and Drug Administration multicenter clinical trial. J Neurosurg. 1998; 89(1): 81-86, doi: 10.3171/jns.1998.89.1.0081, indexed in Pubmed: 9647176.

8. Pandey AS, Koebbe C, Rosenwasser RH, et al. Endovascular coil embolization of ruptured and unruptured posterior circulation aneurysms: review of a 10-year experience. Neurosurgery. 2007; 60(4): 626-637, doi: 10.1227/01.NEU.0000255433.47044.8F, indexed in Pubmed: 17415199.

9. Abecassis IJ, Sen R, Kelly CM, et al. Clinical outcomes and costeffectiveness analysis for the treatment of basilar tip aneurysms. J Neurointerv Surg. 2019; 11(12): 1210-1215, doi: 10.1136/neurintsurg-2019-014747, indexed in Pubmed: 31239332.

10. Twitchell S, Abou-Al-Shaar H, Reese J, et al. Analysis of cerebrovascular aneurysm treatment cost: retrospective cohort comparison of clipping, coiling, and flow diversion. Neurosurg Focus. 2018; 44(5): E3, doi: 10.3171/2018.1.FOCUS17775, indexed in Pubmed: 29712525.

11. James Ling A, D'Urso PS, Madan A. Simultaneous microsurgical and endovascular management of multiple cerebral aneurysms in acute subarachnoid haemorrhage. J Clin Neurosci. 2006; 13(7): 784-788, doi: 10.1016/j.jocn.2005.09.009, indexed in Pubmed: 16815018.

12. Czernicki Z, Dowzenko A, Andrychowski J. Combined treatment of cerebral aneurysms with utilization of clipping and coiling techniques. Neurol Neurochir Pol. 2000; 34(Suppl 6): 21-26, indexed in Pubmed: 11452851.

13. Forbes JA, D'herbemont S, Lehner KR, et al. Feasibility of endoscopic endonasal approach for clip application of cerebral aneurysms: a systematic review. J Neurosurg Sci. 2018; 62(6): 650-657, doi: 10.23736/S0390-5616.18.04405-3, indexed in Pubmed: 29582975.

14. Fischer G, Rediker J, Oertel J. Endoscope- versus microscope-integrated near-infrared indocyanine green videoangiography in aneurysm surgery. J Neurosurg. 2018 [Epub ahead of print]: 1-10, doi: 10.3171/2018.4.JNS172650, indexed in Pubmed: 30485185 .

15. Fischer G, Oertel J, Perneczky A. Endoscopy in aneurysm surgery. Neurosurgery. 2012; 70(2 Suppl Operative): 184-191, doi: 10.1227/ NEU.0b013e3182376a36, indexed in Pubmed: 21937925.

16. Mai JC, Tariq F, Kim LJ, et al. Flow diversion radial artery bypass graft coupled with terminal basilar artery occlusion for the treatment of complex basilar apex aneurysms: operative nuances. Neurosurgery. 2013; 72(2 Suppl Operative): ons116-ons126, doi: 10.1227/NEU.0b013e31827bf2d8, indexed in Pubmed: 23313975.

17. Chwajol M, Munson TA, Alaraj A, et al. Extracranial carotid-vertebral bypass for endovascular access to complex posterior circulation aneurysms: a novel management approach. Neurosurgery. 2012; 70(5): 1296-12303, doi: 10.1227/NEU.0b013e318241374b, indexed in Pubmed: 22083093.

18. Seifert V, Raabe A, Stolke D. Management-related morbidity and mortality in unselected aneurysms of the basilar trunk and vertebrobasilar junction. Acta Neurochir (Wien). 2001; 143(4): 343-349, doi: 10.1007/s007010170088, indexed in Pubmed: 11437287.

19. Sanai N, Tarapore P, Lee AC, et al. The current role of microsurgery for posterior circulation aneurysms: a selective approach in the endovascular era. Neurosurgery. 2008; 62(6): 1236-1253, doi: 10.1227/01.neu.0000333295.59738.de, indexed in Pubmed: 18824990. 
20. Sekhar LN, Tariq F, Morton RP, et al. Basilar tip aneurysms: a microsurgical and endovascular contemporary series of 100 patients. Neurosurgery. 2013; 72(2): 284-299, doi: 10.1227/NEU.0b013e3182797952, indexed in Pubmed: 23147787.

21. Luzzi S, Del Maestro M, Galzio R. Posterior circulation aneurysms: a critical appraisal of a surgical series in endovascular era. Acta Neurochir Suppl. 2021; 132: 39-45, doi: 10.1007/978-3-030-634537_6, indexed in Pubmed: 33973027.
22. Shi X, Qian H, Singh KC, et al. Surgical management of vertebral and basilar artery aneurysms: a single center experience in 41 patients. Acta Neurochir (Wien). 2013; 155(6): 1087-1093, doi: 10.1007/ s00701-013-1656-6, indexed in Pubmed: 23471600.

23. Steiger HJ, Medele R, Brückmann $\mathrm{H}$, et al. Interdisciplinary management results in 100 patients with ruptured and unruptured posterior circulation aneurysms. Acta Neurochir (Wien). 1999; 141(4): 359-367, doi: 10.1007/s007010050311, indexed in Pubmed: 10352745 . 